\title{
Metaphors in communication about pregnancy loss
}

\author{
Jeannette Littlemore and Sarah Turner \\ University of Birmingham $\mid$ Coventry University
}

\begin{abstract}
Pregnancy loss, encompassing miscarriage, stillbirth and termination for foetal abnormality, can be considered a particularly intense and unique form of bereavement, which engenders difficult or painful emotions. When people are talking about such emotions, they have been found to make extensive use of metaphor (Semino, 2011). In this paper, we use metaphor analysis of a small corpus of interviews with individuals in England who have suffered such losses, and people who support them, to explore the nature of the bereavement. In particular, we focus on the ways in which metaphor is used to describe the experience of the loss, the effects that this loss has on people's conceptions of themselves and their bodies, and the implications this has for recovery. We identify a number of characteristics that can lead the bereaved to conceptualise their realities in different ways, which have implications for the grieving process, the ways in which people respond to their grief, and ultimately their recovery.
\end{abstract}

Keywords: metaphor, pregnancy loss, bereavement, emotion, the body

\section{Introduction}

The UK National Health Service (NHS) estimates that across the UK, approximately 1 in 6 known pregnancies end in miscarriage, approximately 1 in every 200 births is a stillbirth, and approximately 2000 terminations for reasons of foetal abnormality are performed each year. ${ }^{1}$ Of all forms of bereavement, pregnancy loss (defined in this study as encompassing all of the above types of loss) can be particularly difficult to deal with. The subject is not widely discussed in British society (NHS Improving Quality, 2014; Renner et al., 2000), the loss itself is usually sudden and unexpected (Kersting \& Wagner, 2012), and there is a lack of

1. www.nhs.uk/conditions/Miscarriage/Pages/Introduction.aspx 
cultural scripts for dealing with perinatal bereavement (Walker \& Walker, 2015). The fact the bereaved are unable to derive comfort from any lived memories with the deceased is also likely to complicate the grieving process (Keefe-Cooperman, 2005; Brier, 2008), and in the case of miscarriage specifically, the lack of public acknowledgement for the deceased and established rituals to mourn them pose additional challenges (Brier, 2008). In cases of both miscarriage and termination for foetal abnormality, guilt is often a factor in the grief (Keefe-Cooperman, 2005), and the act of having to consciously choose to terminate in the case of abnormality may lead to particularly difficult grief due to its added moral component (Lafarge et al., 2013; Maguire et al., 2015).

Pregnancy loss can be considered a site of considerable ambiguity. Cacciatore et al. (2008) convincingly show how Pauline Boss' (1999) work on 'ambiguous loss' can be applied to pregnancy loss, and while their work focuses on stillbirth in an American context, their arguments hold true for earlier losses, too. An ambiguous loss is defined as one in which the status of the lost family member is unknown. Examples could include missing persons, wartime losses where the family member's fate is unknown, or even slow cognitive decline due to conditions such as dementia (Boss, 1999). However, similarities can be drawn in cases of pregnancy loss, where the baby's physical absence clashes with its 'psychological presence' (Cacciatore et al. 2008, p.442), and the ambiguous status of the lost child often contributes to the difficulties of grief because society does not always legitimize such losses. In their study of stillbirth and infant loss in Denmark, Kofod \& Brinkmann (2017) found that bereaved parents struggled with feelings of how much they were 'allowed' to grieve, exacerbated by unhelpful comments from friends and relatives such as 'It was good it happened now instead of later' or 'It is good you didn't get to know him/her first' (p.526) that seemed to demonstrate ambiguity around the status of the lost child. This ambiguity also problematizes familial roles following pregnancy loss, leading bereaved parents to question whether they are still 'parents' or if they ever were (Rando, 1991; Riches \& Dawson, 1996). In addition to these issues, as we will see in this paper, bereavement following pregnancy loss engenders complex emotions, due to its status as a deeply embodied experience, involving the loss of a life not yet lived. These complex factors can lead to a lack of effective support for the bereaved from friends and family, who may be unaware of the significance of the loss (Brier, 2008; Lee \& Slade, 1996).

Studies have shown that when people experience difficult or painful emotions or situations (of which pregnancy loss can be considered an example), they employ metaphor as a tool to help them make sense of and express their experiences (Semino, 2011). More specifically, it has been found that people produce more metaphors when describing intense emotional experiences than when describing actions (Fainsilber and Ortony, 1987) and that they generate more novel metaphors when writing about their own emotional experiences than when 
writing about the feelings of others (Williams-Whitney, Mio and Whitney, 1992). When an experience is not widely shared with the rest of society, metaphor is frequently used to bridge gaps in understanding (Gibbs, 1994). Furthermore, metaphor can often be considered a tool which people can use to help them to understand and come to terms with their own experiences. For example, Gibbs \& Franks (2002) found a particularly high density of powerful metaphors in the narratives produced by women suffering from cancer, which helped them to conceptualise this complex experience.

Despite the attested prevalence of metaphor in discourses surrounding difficult emotional experiences, there has been no research in the metaphor literature on its use in the context of pregnancy loss. In this paper, we analyse the metaphors used by the bereaved when talking about this emotionally-complex, potentially isolating experience, in order to gain insights into their thinking processes. We hope that this will ultimately inform improved care pathways.

Our research takes as its point of departure the notion that metaphor can be considered as growing up from the surrounding ecological context and the affordances this gives. Metaphor, therefore, is both a cognitive and social phenomenon, and is not restricted to merely the linguistic (e.g., Jensen \& Cuffari, 2014; Jensen, 2017). Metaphorical action also deserves attention, and our research demonstrates that a key component of the experience of loss involves metaphorical (and sometimes metonymic) enactment and memorialisation. In recognising this, we align ourselves with recent trends in cognitive science that view cognition as occurring not solely 'within the skull' but as an enacted process, situated in the world (Noë, 2009). Under this theory, objects in the external world take on a central part in human cognition: 'thus, the mind is not simply in the head, but is organismically embodied, contextually embedded, and environmentally extended and distributed' (Brinkmann \& Kofod, 2018, p. 161). Such a view has already been applied to the experience of grief by Brinkmann \& Kofod (2018), who note that objects and activities within the environmental context of grief and bereavement - funerals, photographs, belongings, etc - should be considered parts of the emotion of grief. Thus, our research is not restricted to linguistic metaphor (i.e. metaphor found in language), but considers objects and actions as similar potential grounds for metaphorical cognition and action. These could include the use of images, symbols, and ritual to convey meaning metaphorically, as shall be seen later on.

If, as Brinkmann \& Kofod argue, the experience of grief is thus dependent on environmental and social factors, we can expect the experience of pregnancy loss to be particularly marked in terms of the reduced affordances that it gives to the grief. This is due to the taboo nature of pregnancy loss, the silence that surrounds it, and the lack of cultural 'scripts' to respond to it, as mentioned above. This lack of 'scripts' becomes particularly relevant to the experience of grief when we consider grief as a normative experience, that is, performed 'relative to cultural norms' 
(Kofod \& Brinkmann, 2017, p.520). In the absence of cultural norms scaffolding grief following pregnancy loss, bereaved individuals are likely to struggle not only with the pain of bereavement, but also with the lack of cultural support, as Kofod \& Brinkmann found. While their work focused on infant loss, the same can reasonably be expected to apply to pregnancy loss, too. It is from this understanding that we proceed.

In this study, we focus on metaphor use in a small corpus of interviews with individuals who have suffered such losses in England, and people who support them. We explore the ways in which metaphor is used to describe the experience of the loss, its effects on people's conceptions of themselves and their bodies, and the implications this has for recovery.

\section{Methodology}

This research forms part of the 'Death before Birth' project, a 2-year ESRC-funded ${ }^{2}$ study running from 2016-18 and granted ethical approval by the University of Birmingham. In order to obtain the data required for the current study, three members of the research team ${ }^{3}$ interviewed 35 people, the majority of whom had experienced miscarriage, termination for foetal abnormality (hereafter referred to as 'termination'), or stillbirth in England a minimum of six months before the interview. Written, informed consent was obtained from all participants. All participants were over 18 and living in England. Of the 35 participants, 31 were women who had experienced a loss, three were male partners of the female participants, and one was a friend of the bereaved (see Figure 1 and Appendix 1). All quotations are taken from interviews with the women unless otherwise stated. We recognise that the dataset is somewhat unbalanced in terms of gender and experience, but this is due to the partially self-selecting nature of the recruitment process. Participants were recruited through three UK-based pregnancy loss charities who were partners in our study. These were: the Stillbirth and Neonatal Death Charity (Sands), the Miscarriage Association (MA) and Antenatal Results and Choices (ARC). Although we were able to recruit women who had experienced pregnancy loss, there was less response from their partners. We also recognise that because we recruited our participants through support organisations, our sample is skewed towards those who felt the need for the support that these charities offer. Therefore, their experiences may not be shared by everyone who goes through pregnancy loss,

2. Economic and Social Research Council, UK. Project reference number: ES/Noo8359/1.

3. Prof Danielle Fuller, Dr Karolina Kuberska and Dr Sheelagh McGuinness. 
as people's grief responses differ in nature and in strength. However, our project is designed to improve care for those who are finding it difficult to come to terms with their pregnancy loss, so we wanted to hear from people who needed this care most. Finally, it should be noted that this study is specific to the English context, and further research would be necessary to establish the extent to which our findings are generalizable across other cultural contexts.

The interviews were semi-structured and 60-90 minutes in length. During these interviews the interviewers explored the participants' experiences of pregnancy loss, focusing on what they did with their baby ${ }^{4}$ in terms of funerary arrangements, and how they reached their decisions and the emotional effects of their loss. The team also interviewed 16 individuals who provide support for the bereaved, many of whom had themselves experienced pregnancy loss.

Semi-structured interviews with:

- Individuals who work for charities that support bereaved individuals $(n=16)$;

- Women who had experienced stillbirth $(n=9)$, miscarriage $(n=11)$; and termination following a diagnosis of foetal anomaly $(n=11)$;

- Partners and friends of these women $(n=4)$.

Figure 1. Details of participants in the study

The interviews were face-to-face where possible, otherwise conducted via skype or by telephone. The interviews were audio-recorded, then transcribed. ${ }^{5}$

The transcripts were uploaded into NVivo for coding. NVivo is a qualitative research package which is used to assist in data organisation and annotation using a set of user-defined categories. For our analysis, we focused on the main parts of the interviews where individuals were explicitly talking about their experience of the loss, their ways of dealing with it, the choices they made regarding memorialisation and remembrance, and people's reactions to their loss. ${ }^{6}$ We (Littlemore and Turner) began by identifying the metaphors in these parts of the interviews. In order to decide whether an utterance was metaphorical or not, we employed an adapted version of the PRAGGLEJAZ Group (2007) Metaphor Identification

4. In this paper, we use the term 'baby' to refer to losses at any stage of pregnancy, although we recognise that others may use different terminology.

5. The full anonymised transcripts of our interviews are publicly available on the UK Data Service website https://ukdataservice.ac.uk/

6. It should be noted that our interviews also contained housekeeping components and small talk. These were not coded for metaphor use. 
Procedure $^{7}$ (MIP), which we combined with Cameron's (2003) vehicle identification procedure to identify metaphors at the level of the phrase. We then classified the metaphors into broad categories that reflected the semantic fields to which the vehicle terms belonged. For example, in our identification of these metaphor categories, we did not make any assumptions about conceptual metaphor or source domains, so some of the categories of metaphor that we discuss cannot be found in established metaphor lists (e.g., Lakoff and Johnson, 1980; Grady, 1997). Sixty-seven categories of metaphor were identified, including metaphors involving space, darkness and light, movement, growth, ascent and descent, and containment. For example, in the category of liquid-based metaphors, we had 'a whirlpool', 'outpouring of grief', and 'drown in their grief' as all of these trigger the semantic field of liquid. In some cases, one linguistic metaphor could be assigned to more than one metaphor category and some categories were more over-arching than others. So that we would not miss any important information, we adopted a maximally inclusive approach in which all categories were treated at the same level despite the fact that some categories may presuppose others. For example, consider the following linguistic metaphor 'I just burst into tears cos I was like I feel it's OK for some of this to come out now. We annotated this under the following metaphor categories:

- container

- inside and outside

- reification

A full list of the metaphor categories identified with examples and the number of metaphors found in each category is provided in Appendix 2. Through an iterative process, we identified a set of 71 topics that these metaphors were being used to talk about (see Appendix 3). These included for example, 'the diagnosis', 'memory-making' and 'recovery'. Each metaphorical chunk of language was assigned to at least one topic.

The coding schemes that we used for the identification of the topics and the metaphor categories were developed by three coders through joint analyses of the first five transcripts. Subsequent transcripts were then coded individually. Each transcript was checked by a second coder and marginal cases were discussed until agreement was reached.

From this stage of the analysis we were able to identify a number of metaphor categories which were common in our dataset to talk about a number of topics and from this we were able to consider the implications of these metaphors and

7. The methodology was adapted from the MIP in that we only included open class lexical units and allowed for changes in part of speech. 
the insights that they might provide into the ways in which the individuals are experiencing their loss.

\section{Findings}

We identified 67 metaphor categories in our data set which were used to talk about 71 topics. Here we focus on metaphor categories describing the impact of the loss on the individual, in terms of the ways they affect their embodied experience, their relationship with their own body, and their perception of reality. In closing, we look at how they experience recovery in metaphorical terms.

\subsection{Embodied experience}

Many of the participants in our study described their grief in very physical terms, as we can see in the following examples: ${ }^{8}$

You think you've got everything together and then you sort of have the rug ... pulled out from under

[you] [WP4-T1-FA-1]

[those feelings] can really eat at you

$\left[\mathrm{WP}_{4}-\mathrm{T}_{5}-\mathrm{M}-4\right]$

The miscarriage broke me. And not much in my like has broken me before. I just kind of .... get on with things and it broke me.

[WP 4 -T12-M-9]

These metaphors imply being acted upon by an external force, and an associated loss of agency. Whilst these particular metaphors are conventional and are not necessarily specific to this type of loss, other bodily based metaphors were more marked because they appeared to involve a conflation of the metaphorical and literal experiences. This is understandable as the women involved were experiencing a physical loss (i.e. the loss of the baby) at the same time as a metaphorical loss (i.e. the loss of part of themselves in a more abstract sense). This can be seen in the following examples:

Yes for instance erm I feel a lot stronger cos not many people go through this and it err it like it's not like losing a parent or erm a it's not like I've lost grandparents and even friends that have died but it's NOT like that because it's part of you and

8. In this paper we underline metaphors that comprise meaningful stretches of language (Cameron, 2003) rather than individual vehicles. Only those metaphors that are under discussion are underlined. 
he's a part of me it's like I lost myself for a long long time and then you have to try and rebuild yourself and your confidence and everything

[WP4-T11-FA-3]

I I've still I I've feel (.) part of me is missing.

[WP4-T21-FA-9]

we're all sort of left like with this emptiness inside of us which is very physical as well as emotional

[WP4-T9-M-8]

In order to compensate for this loss, many of the women we interviewed had had their baby's name or an associated symbol tattooed on their body. This can be construed as metonymic enactment reminiscent of Brinkmann \& Kofod's (2018) view of grief as an extended emotion. It indicates a desire to return to the body what was lost through a symbolic 'reunification':

I wanted to get [the tattoo] as soon as possible. I was like putting her on my body ${ }^{9}$ again.

[WP4-T10-FA-2]

This enactment sometimes involved other members of the family:

and [PARTNER]'s got a tattoo of so his handprints were taken in the hospital and he's had that tattooed on the inside of his arm. Erm he's got a couple of tattoos but this one's still nice and subtle it's there ... [DAUGHTER] gives it high fives now and again which is quite nice ... give [NAME] a high five and she'll tap it yeah it's quite cute. So yeah so he's present in that way that's our way of commemorating I think.

[WP4-T25-S4]

The symbols that people used to help them come to terms with the loss were sometimes highly idiosyncratic and personal, as we can see in the following example, where the couple used popcorn to help them memorialise the experience, again through a process of metonymic enactment:

When I first found out we were pregnant we'd, well, the baby- like I said, people call them 'bean' or whatever, but we used to call it Popcorn. So we got popcorn and we sat and shared together. We just sat together ... I'll probably, like, later, sort of, down the line, maybe get a tattoo of a box of popcorn. [...] I said we should call this instead of calling it Bump we should call it Popcorn. Like a little, you know, little bit of popcorn poppin' away doing whatever it's doing. [PARTNER] loved that because, erm, [DAUGHTER] and I we used to play what she calls the Popcorn Game. Basically you stand one side of the room and just chuck it at each other's gobs ... so it was just a funny family thing to do. Erm, so on, yeah the anniversary of us finding out... that, erm, 'nobody was home' [she imitates the

9. Instances of metaphorical and metonymic enactment are indicated in italics. 
way she was told about the loss], we got some popcorn and we shared some popcorn together and we just had like a little me and him moment. [WP4-T9-M-8]

Other examples of symbolic metaphorical enactment were more conventional and made use of themes from nature, as we can see in the following example:

One of my friend's mum was lovely. This is what I was going back to, some people unexpectedly were just so appropriate and lovely. Anyway I have a friend's mum who just came up trumps ... planted a snowdrop. And every year I get a picture of how this snowdrop's doing which is really lovely. And I think- I've got a feeling snowdrop is associated with children or stillborn death. I don't know, I might've just made this up but snowdrops, I'm gonna say, is what I think of.

$\left[\mathrm{WP}_{4}-\mathrm{T} 26-\mathrm{S}-5\right]$

Other cases involved half-remembered tropes from mythology and religion:

uh we had a five pence piece- when he died someone'd always said you that you need um money to pay the gatekeeper ... to go through heaven and it just stuck in my head, um, so we put a $5 p$ in his hand, um, like, before he went so had kept... another $5 p$ and put it in [the memory box].

[WP4-T28-S-7]

Here the participant seems to be conflating Greek mythology of Charon ferrying dead souls across the River Styx and Christian ideas of Saint Peter as a gatekeeper. These examples show the range of ways in which people engage in symbolic metaphorical and metonymic activity, ranging from the highly creative to the more conventional. Their use of metaphor in the grieving process involves actions as well as words.

We have seen in this section that pregnancy loss is construed as an embodied experience, which can lead to a range of forms of metaphorical behaviour, often involving their bodies (e.g. through tattoos). As we will see below, the fact that people are going through an emotionally intense experience and that this experience is strongly embodied also seems to lead to a fundamental change in (a) their relationships with their bodies and (b) the way their bodies exist in time and space. This change can be so fundamental as to make the participants feel as if they are experiencing a different reality. This is demonstrated through a range of ways in which metaphorical language was used, which we address in the next two sections.

\subsection{Relationships with the body}

The language that the bereaved women in our study used to talk about the relationship they had with their bodies following loss often implied an 'otherisation' and subsequent personification of them. This otherisation was demonstrated 
through a distancing and separation of the self from the body, which enabled them to personify and to attribute a separate agency to their bodies:

I knew my body could do what it had to do

[WP4-T24-M-11]

Mine.. stopped growing at six weeks but I was twelve to thirteen weeks (.) pregnant cause my body hadn't realised that nothing was happening [WP4-T9-M-8]

it'd been several weeks already and that my body hadn't caught on that I'd probably need to have some kind of induction

[WP4-T7-M-6]

The body's obviously very good at keeping hold of babies that it shouldn't do, because it did that four times [WP4-T1-FA-1]

And in some cases, once the body had been personified and distanced from the 'self', it could be 'blamed' for the pregnancy loss:

My primary feeling, the first feeling was that my body had failed me totally

[WP4-T7-M-6]

There is a whole range of emotions from feeling really angry with my body and myself not knowing that it was happening and for my body for letting me down

$\left[\mathrm{WP}_{4}-\mathrm{T} 7 \mathrm{-M}-6\right]$

The construction of separate entities went beyond the idea of the self and the body being separate, to include a 'split self' metaphor in which participants are seeing their minds and brains (or parts of their minds and brains) as being separate from their main identities. In some cases this was a conscious decision on the part of the bereaved, perhaps as a coping mechanism, and in others it was an uncontrollable consequence of the bereavement, with these two points lying at opposite ends of a gradual scale: 
I completely separated myself from the pregnancy, it was almost - it was just a scientific process that was happening, that was how I dealt with it really

[WP4-T29-S-8]

So if I go there and think about them and cry maybe I can go home and cry a bit less because I can siphon off my crying into that part [WP4-T14-FA-4]

the all thoughts get all jumbled and you get claustrophobic and it all just keeps going round and round so you need I need somewhere else to try and put it

[WP4-T14-FA-4]

I think the sensible part of my head KNEW (that it wasn't going to happen)

[WP4-T19-FA-8]

I think you just put up a barrier of being normal to protect yourself but your brain isn't really functioning the same way your brain is just getting you through the motions rather than ... disconnect from what's happening in your life EMOTIONALLY to get you through the day [WP4-T19-FA-8]

I was a mess. So I did really pull it together for [the labour] but even now I think I wasn't really there

[WP4-T30-S-9]

Less retrospective agency

\subsection{Experiencing a different reality}

The final example in the section above adds a spatial component to this separation of self, or self and body, which allows for the possibility of the bereaved inhabiting a different world and a different reality. This experience, which is often very isolating, can affect them on such a level that they consider themselves to become 'different people' as a result of the experience. This can be considered similar to what Parkes (1996, p.200) calls the 'psychosocial transition' component of bereavement, referring to a bereaved individual's 'sense of dislocation between the world that is and the world that should be', followed by a move 'towards acceptance and the adoption of a new model of the world'.

In some cases the participants employed the metaphor of taking a different 'journey' and/or living in a different 'world' which seemed to show that pregnancy loss had shaped the ways in which they experienced the world: 
It's a bit like being thrown down a path that you didn't expect to go on. A bit like Sliding Doors? ${ }^{10} \ldots$ that suddenly something's happened to you ... you're going that way and you keep looking but and eventually you can't see that path anymore and that's your new path. So you carry on your life but you're in a new world. It's sometimes I compare it like a parallel world. Like I can see what our life would've been (.) but this is where we are now. I never expected it but we're creating our own (.) that's how (.) cause I think the (.) the crux of it is that it will change everything about your life forever.

$\left[\mathrm{WP}_{4}-\mathrm{T}_{25}-\mathrm{S}_{4}\right]$

This is understood by people who are there to support the bereaved, as these two examples by support workers demonstrate:

when you're grieving you can sort of enter sort of a grief world where y-you start to push people away

this is what I describe to parents if the world is going round that's the world you know and then when you have a baby that's died you get off; you know the world is still going around and then as time goes on you know you might go round a couple of times and then get off again and get on again do you know what I mean and then gradually you'll get back on but you have to do it at your own pace so it's kind of dipping in and out you know

[WP3-T14-Support]

The presence of a different reality can lead to decisions and ideas that seek to integrate the two realities. One of the most common ways in which this took place was in reconciling the death of the baby with a 'reality' in which the lost babies were, on some level, still very much 'alive'. One parent commented that 'I wanted to bury him with other babies to keep him company' and one of the healthcare professionals observed that it was important for the parents to be allowed to cuddle and wash the stillborn baby. This view was also expressed by one of the parents who was concerned about her baby attending the post mortem on his own:

I went back the following day actually on my own cause I wanted to see him again and I wanted to give him the soft toy and the photo of us because those are the things that he was going to go to the post-mortem with. Didn't want him to be on his own when he went.

[WP4-T2O-M-10]

These cases of metaphorical thinking reflect continuing attachments to the baby. In the case of pregnancy loss, these bonds can be considered unique, as most aspects of the relationship between parent and baby remain unrealised (Uren \&

10. Sliding Doors is a 1998 British-American film directed by Peter Howitt, starring Gwyneth Paltrow and John Hannah. The film alternates between the two paths that the central character's life might have taken, depending on whether or not she made it through the doors in time to catch a train. 
Wastell, 2002, p.282). Such ongoing bonds, however, intensify the experience of bereavement, with stronger bonds having been shown to cause stronger experiences of grief (Neimeyer et al., 2006). The existence of these bonds is also likely to contribute to the isolation bereaved parents feel from those around them, who have not been able to develop such bonds of their own to such an extent. The bonds experienced by the parents are also in many ways symbolic, relating to what might have been rather than what was (Malacrida, 1998). The metaphorical thoughts and actions described here may also reflect the fact that these people find themselves in a situation where what was real (i.e. the expected baby and future life with them) has become unreal, and what is hitherto unthought-of (i.e. the baby's death) has become real. This leads to the juxtaposition of two conflicting realities which parents seek to integrate by engaging in actions they would take in the reality where the baby was still alive, in the reality where it is not. As will be shown later, this idea of 'integration' is a significant feature of recovery, and is often achieved through regaining a measure of control over the grief.

These integrative behaviours are recognised and encouraged by healthcare workers, as shown by this extract from an interview with two hospital workers who work with bereaved parents. It demonstrates a father engaging in actions he would take not only in a reality where the baby was alive, but a reality set many years in the future, thus adding a temporal component to the presence of different realities:

A: Before the funeral, it's your time to do the things that you wanted to do, so I understand that many dreams you had aren't achievable, but if there are some, our job is to help you dream the dream basically, and lots of them are to do with dad, but we've had dad who always wanted beer, and he said I want a can of beer, dad and lad, we've facilitated that

B: Yeah he wanted a can of beer with his da- his son and sadly his son was stillborn, so we let him have some beer in the family room with his baby

$\left[\mathrm{WP}_{2}-\mathrm{T} 6-\mathrm{BCP} 3\right]^{11}$

In this extract, the father metaphorically 'shared a beer' with his son, an activity that he might normally have engaged in when his son reached adulthood. This allows the father to reconcile two incompatible realities; one in which he experiences the future that he would have had, and one in which he cannot. Although this is not a linguistic metaphor, we see it as an example of a metaphorical enactment. It is not literally a celebration of a son reaching adulthood but more a symbolic behav-

11. This extract and the next are taken from an interview that we conducted with two bereavement care midwives. We conducted 12 such interviews. They are not listed in our Appendices as we have not systematically explored their content in this paper. 
iour in which the act brings a salient moment from a hoped for, but non-existent future into the present. The comparison is between a reality of loss and a future of celebration. This isn't an isolated case; the midwives recognised the importance of prompting bereaved families to consider what they would have wanted to do with their child had it lived, with a view to bringing these wishes into reality. These actions often involved the whole family, including other living children.

A: He dreamt the dream ... and that's his memory ... we learned that this is the time to capture the memories, we've had a dad who always wanted to read a goodnight story to all his children together, so we did that. So now when I... speak to the families and say to them, is there a dream that you're dreaming, let's do it

[WP2-T6-BCPo3]

The behaviours exemplified above also demonstrate a key factor that differentiates the grief of pregnancy loss from other forms of grief. In adult grief, the bereaved can often look back on a lifetime of memories, drawing on them to support them through the grieving process. However, in the case of pregnancy loss, the grief is directed towards a potential life, memories that have not yet been formed except in the hopes and expectations that may begin from the moment pregnancy is confirmed.

I think what the GP and other people around us didn't understand was we didn't just lose a four or five week old embryo or foetus or whatever it is at that point we'd lost our future.

[WP4-T24-M-11]

Again, this demonstrates a convergence of two different temporal realities, with an 'irreal' future (i.e. the future with a living child) having an impact on the 'real' present. The integrative behaviours discussed above further bring this future into the present, making it real and allowing the fact that it will not occur to be grieved.

This integrative behaviour can continue long past the point of loss, and can play an important role in the recovery process. In this case, it often includes behaviour which validates the experience of the pregnancy loss and honours the legacy of the baby. One couple commented for example that their work for pregnancy loss charities constituted the only way in which they could 'parent' their lost baby; they felt the need to engage in behaviours that could replace parenting, but these were by necessity directed towards other targets. Similarly, many parents expressed a desire for something positive to come out of their loss, whether this was through sharing their story with others, engaging in the work of the support organisations, or even through participating in projects such as ours:

It's really for me as a mother but.... it's important to know that his story can go on and help other women. And, you know, also to inform how we think about pregnancy loss, so I'm just really glad to be part of the project.

[WP4-T2O-M-10] 
Such an effort to ensure that something positive resulted from the loss is not unique to our data, as Cacciatore et al. (2018) note in their research into the positive effects of volunteerism following stillbirth. Indeed, it has been identified as an important step towards recovery (Folkman, 2001). For Neimeyer (2001) and Neimeyer and Anderson (2002), this 'benefit finding' is one of three activities through which bereaved individuals reconstruct meaning following a loss, alongside 'sense-making' and 'identity change' (see also Rando, 1993).

\subsection{Recovery}

Throughout this paper, we have argued that pregnancy loss involves the presence of two different, conflicting realities, and that this is demonstrated through metaphors relating to the body and temporal/spatial shifts. The process of coming to terms with the loss involves integrating these two realities, to the point that they become a single, coherent 'new normal'. The way this is done often involves regaining agency and control over the grief, while recognising and accepting that it does not go away. The participant in the example below reifies her grief, enabling her to take control of it and 'change it', acknowledging her role in actively reworking her experience of grief and using it in positive ways:

It just sort of went on and then it just - not faded out a bit but I changed it so like we got the dog, um, not that she cared, and I started doing art again which was brilliant... I've been able to use that grief and, um, the experience like I said to help others or I channel it into my art

[WP 4-T9-M-8]

Another participant personified her grief. While she took less of an active role in changing her grief, her recovery involved accepting its presence in her life and seeing the changes that it wrought on her as being positive, as they acknowledged the importance and significance of her loss.

I went and spoke to the doctor and they just said it'd be something I just got over basically they didn't provide any kind of support or anything. They just said, "give it time, give it time”... you know, I don't think I'll- well, you don't 'get over it', do you. I don't think I'll ever get over it. You know, I think you just learn to, urm - it just lives alongside you and changes you. But I don't mind that. I kind of think I ought to be changed.

[WP4-T29-S-8]

These two examples differ from each other in that one has the participant changing her grief and the other has the grief changing her, but in both cases a change has occurred. Indeed, a number of participants expressed that the experience changed them to the point that they felt as if they had become a different person, something considered a necessary part of a psychosocial transition by Parkes 
(1996), and a crucial part of the grief process by Rando (1993), Neimeyer (2001) and Neimeyer \& Anderson (2002) (see above):

You can't have a break from grief. It's with you all the time. In varying degrees and it's how you deal with it. So just be prepared for it to be all consuming and life changing ... and just don't try to be who you were before cause you can't be I don't see how you could be. It changes everything.

[WP4-T25-S4]

But I go through it and I came out the other side and ...you can look back and ...think about it almost sort of looking at it as if you're another person

[WP4-T15-FA-5]

The nature of these changes varied from individual to individual, with some participants expressing positive changes such as becoming more empathic, more supportive, and more resilient to other problems in their lives that they now considered to be less important. Among participants with strong religious faiths, their loss often had a strengthening effect on the way they experienced their faith.

These examples demonstrate a view of recovery that does not involve a return to a pre-loss state; instead the loss becomes a part of one's life that can be reclaimed and worked around. But crucially, the loss is still there, reified as something that is carried, or personified as something that 'lives alongside you'. The idea of bereavement having permanent effects, often leading to positive psychological changes including resilience, empathy and independence, is well-established in the bereavement literature, with such 'identity change' constituting a key part of meaning-making and recovery (Gillies \& Neimeyer, 2006; Rando, 1993). Unfortunately, such a view of recovery is not universally acknowledged by supporters and healthcare workers, with some patients being told they would 'get over it' in time. When it is acknowledged, however, it has a positive effect on parents, with one support worker explaining the grief process as follows:

You don't go back to normal, you have a new normal and I remember one mum sounding so relieved. She was like, oh yeah, a new normal, you know and that really helped her... because going back to normal means your baby didn't exist.

[WP3-T7-Support]

\section{Conclusion}

Our analysis of the metaphors used by people who have experienced pregnancy loss in England has underlined its particularly isolating and challenging nature. We would also propose that it has implications for metaphor theory. Our study has shown that metaphor as a meaning-making phenomenon goes beyond the linguistic. It extends to image (e.g. popcorn), behaviour (e.g. beer-drinking), 
and ascribed meaning (e.g. a baby you know to be dead still needs 'parenting'). This makes traditional approaches to metaphor research that take conceptual metaphor theory as their departure point very difficult, as when people find themselves in emotionally challenging situations they often need to depart from conventional metaphorical scripts. There may also be cases where it is not possible to identify a metaphor by using traditional metaphor identification procedures and it is not always possible to identify a clear source and target domain. For example, when parents engage in parenting behaviours towards their dead baby, the liminal status of the baby in their mind (i.e. where the baby is dead and yet not dead) means that this is not a straightforward animacy metaphor.

We have seen that grief is a normative experience, drawing on cultural and societal scripts and rituals. In the case of pregnancy loss, however, these norms are not present. We have also seen that grief tends to be predicated on particular bonds or attachments with the deceased. In the case of pregnancy loss parents have not been able to bond with a living child so the bonds that they experience are with a potential child who was never part of the external world. What is being grieved, therefore, is a future life. Because these bonds are difficult to share with people who did not experience the pregnancy at close hand, this contributes to feelings of isolation.

Our metaphor analysis has provided insights into the nature of the thinking processes that both contribute to and result from these feelings of isolation. We have seen that in pregnancy loss the embodied nature of grief is reinforced by the physical nature of the experience. The loss is both literally and metaphorically situated with the body. The unique nature of this experience makes it difficult to share. Because the death often occurs within the body, or shortly following birth, this heightens the silence and invisibility of these losses. The embodied nature of pregnancy loss also affects the relationship that people subsequently have with their bodies. We saw that people often talked in terms of separation from their bodies, a fragmentation of the body from the mind, and in some cases, subsequently blamed their bodies for the loss.

We have also demonstrated that pregnancy loss involves a shift into a 'different reality' which is often metaphorically or metonymically enacted, with parents engaging in parenting behaviours despite the loss of their child. While this is not specific to perinatal bereavement, we would argue that it is particularly marked in the context of pregnancy loss. This is because such a loss is usually sudden and unexpected and there is no time to prepare for it, which contributes to the severity of the grief experienced (Parkes, 1996). Furthermore, pregnancy loss involves a loss of future life, which can be contrasted with grief following an adult death in which the bereaved can draw on memories of the deceased's life. They have also been able to perform the roles and attachments these relationships bring, whereas 
in contrast those who have experienced pregnancy loss have had no opportunity to do so. As we have seen, they may also seek other outlets that will allow them to perform metaphorical parenting roles e.g. volunteering. The reality shift may be particularly marked by the lack of scripts surrounding pregnancy loss, which leads some bereaved parents to have to come to terms with a new sense of reality.

The lack of external scripts is particularly problematic in terms of the experience of grief because, as we have seen, grief (along with cognition more generally) is not limited to the individual, or indeed to their own consciousness. Instead, it finds focus in the external world, attaching itself to physical artefacts such as photos, symbols, music, and ritual. When these things are absent, the experience of grief can become more difficult to resolve. In response to this, we have seen that bereaved individuals do engage in metaphorical action, and that this may involve very personalised symbols that are exclusive to their own experience (such as the 'popcorn' example, above).

Recovery from pregnancy loss involves integrating the conflicting realities that the loss creates, through regaining agency and control over the grief, while recognising and accepting that it does not go away. This is demonstrated through metaphorical language that reifies and personifies grief, giving it the agency to change the bereaved. This is considered to be a positive outcome by the bereaved, reminiscent of Rando's (1993) work on the need to let go of old ideas about the world and to form a new identity following a loss.

We recognise that our study is restricted to an English context, and that further research should be undertaken to examine the extent to which our findings hold true in other contexts. However, the findings from this study have implications for those who are in a position to support people who have experienced pregnancy loss. It is important to understand that people who have been through this experience are often in a completely different place psychologically as a result of the experience. This is exacerbated by the fact that the loss is as much physical as it is metaphorical and the bereaved are likely to experience grief as being something permanent, which changes in form but never leaves. The bereaved may act in ways that seem slightly unusual, and may even seem to become 'different people' with changed priorities following the loss. Effective support often involves acceptance of these changed realities.

\section{Acknowledgements}

We would like to thank the Economic and Social Research Council for funding this research, and our project partners (The Stillbirth and Neonatal Death Charity, the Miscarriage Association, Antenatal Results and Choices and the Human Tissue Authority) for their invaluable sup- 
port. We are also grateful to our co-researchers on the 'Death before Birth' project, Professor Danielle Fuller, Dr Sheelagh McGuinness, Dr Karolina Kuberska Research Associate and Meera Burgess for their contribution to this research and for the many rewarding, insightful and interdisciplinary discussions that we have had about this topic. We are also grateful to our Research Assistant, Patrick Dandy, who helped with the data processing and with the formatting of this paper. Finally, and most importantly, we are indebted to all our participants, without whom this study would not have been possible. We would also like to acknowledge Danny, the son of one of our participants.

\section{References}

Boss, P. (1999). Ambiguous Loss: Learning to Live with Unresolved Grief. Cambridge, MA: Harvard University Press.

Brier, N. (2008). Grief Following Miscarriage: A Comprehensive Review of the Literature. Journal of Women's Health 17(3), 451-464. https://doi.org/10.1089/jwh.2007.0505

Brinkmann, S., \& Kofod, E. (2018). Grief as an extended emotion. Culture \& Psychology, 24(2), 16o-173. https://doi.org/10.1177/1354067X17723328

Cacciatore, J., DeFrain, J., \& Jones, K.L.C. (2008). When a Baby Dies: Ambiguity and Stillbirth. Marriage \& Family Review 44(4), 439-454. https://doi.org/10.1080/01494920802454017

Cacciatore, J., Blood, C., \& Kurker, S. (2018). From “Silent Birth” to Voices Heard: Volunteering, Meaning, and Posttraumatic Growth After Stillbirth. Illness, Crisis \& Loss 26(1), 23-39. https://doi.org/10.1177/1054137317740799

Cameron, L. (2003). Metaphor in Educational Discourse. London: Continuum.

Fainsilber, L., \& Ortony, A. (1987). Metaphorical uses of language in the expression of emotions. Metaphor and Symbolic Activity 2(4), 239-250.

https://doi.org/10.1207/s15327868ms0204_2

Folkman, S.F. (2001). Revised coping theory and the process of bereavement. In H. Schut (Ed.), Handbook of bereavement research: consequences, coping, and care. Washington: American Psychological Association, pp. 563-584. https://doi.org/10.1037/10436-024

Gibbs, R. (1994). The Poetics of Metaphor. Cambridge: Cambridge University Press.

Gibbs, R., \& Franks, H. (2002). Embodied metaphor in women's narratives about their experiences with cancer. Health Communication 14(2), 139-165. https://doi.org/10.1207/S15327027HC1402_1

Gillies, J., \& Neimeyer, R.A. (2006). Loss, Grief, and the Search for Significance: Toward a Model of Meaning Reconstruction in Bereavement. Journal of Constructivist Psychology 19(1), 31-65. https://doi.org/10.1080/10720530500311182

Grady, J. (1997). Foundations of meaning: primary metaphors and primary scenes, Unpublished PhD Thesis, University of California at Berkeley.

Jensen, T.W. (2017). Doing Metaphor: An Ecological Perspective on Metaphoricity in Discourse. In B. Hampe (Ed.), Metaphor: Embodied Cognition and Discourse. Cambridge: Cambridge University Press, pp.257-276. https://doi.org/10.1017/9781108182324.015

Jensen, T.W., \& Cuffari, E. (2014). Doubleness in experience: toward a distributed enactive approach to metaphoricity. Metaphor and Symbol, 29(4), pp.278-297.

https://doi.org/10.1080/10926488.2014.948798 
Keefe-Cooperman, K. (2005). A comparison of grief as related to miscarriage and termination for fetal abnormality. OMEGA 5o(4), 281-300. https://doi.org/10.2190/QFDW-LGEY-CYLM-N4LW

Kersting, A., \& Wagner, B. (2012). Complicated grief after perinatal loss. Dialogues in Clinical Neuroscience 14(2), 187-194.

Kofod, E., \& Brinkmann, S. (2017). Grief as a normative phenomenon: The diffuse and ambivalent normativity of infant loss and parental grieving in contemporary Western culture. Culture \& Psychology 23(4), 519-533. https://doi.org/10.1177/1354067X17692294

Lafarge, C., Mitchell, K., \& Fox, P. (2013). Women's experiences of coping with pregnancy termination for fetal abnormality. Qualitative Health Research 23(7), 924-936. https://doi.org/10.1177/1049732313484198

Lakoff, G. and Johnson, M. (1980). Metaphor we Live By, Chicago: University of Chicago Press.

Lee, C., \& Slade, P. (1996). Miscarriage as a traumatic event: A review of the literature and new implications for intervention. Journal of Psychosomatic Research 4o(3), 235-244. https://doi.org/10.1016/0022-3999(95)00579-X

Maguire, M., Light, A., Kuppermann, M., Dalton, V.K., Steinauer, J.E., \& Kerns, J.L. (2015). Grief after second-trimester termination for fetal anomaly: a qualitative study.

Contraception 91, 234-239. https://doi.org/10.1016/j.contraception.2014.11.015

Malacrida, C. (1998). Mourning the Dreams: How Parents Create Meaning from Miscarriage, Stillbirth \& Early Infant Death. Alberta, Canada: Qual Institute Press.

Neimeyer, R.A. (2001). Meaning reconstruction \& the experience of loss. American Psychological Association. https://doi.org/10.1037/10397-000

Neimeyer, R.A., \& Anderson, A. (2002). Meaning reconstruction theory. In N. Thompson \& J. Campling (eds.) Loss and Grief. London: Palgrave, pp. 45-64. https://doi.org/10.1007/978-1-4039-1404-0_4

Neimeyer, R.A., Baldwin, S.A., \& Gillies, J. (2006). Continuing Bonds and Reconstructing Meaning: Mitigating Complications in Bereavement. Death Studies 3o(8), 715-738. https://doi.org/10.1080/07481180600848322

NHS (2014). Improving Quality, http://www.nhsiq.nhs.uk/

Noë, A. (2009). Out of our heads: Why you are not your brain and other lessons from the biology of consciousness. New York: Macmillan.

Parkes, C.M. (1996). Bereavement: Studies of grief in adult life (3rd ed.) London: Routledge. PRAGGLEJAZ Group. (2007). MIP: A method for identifying metaphorically used words in discourse. Metaphor and Symbol 22(1), 1-39. https://doi.org/10.1080/10926480709336752

Rando, T.A. (1991). Parental adjustment to the loss of a child. In D. Papadatou \& C. Papadatos (Eds.), Children and Death. New York: Hemisphere Publishing, pp. 233-253.

Rando, T.A. (1993). Treatment of Complicated Mourning. Champaign, Illinois: Research Press.

Renner, C.H., Verdekal, S., Brier, S., \& Fallucca, G. (2000). The Meaning of Miscarriage to Others: Is it an Unrecognised Loss? Journal of Personal and Interpersonal Loss 5, 65-76. https://doi.org/10.1080/10811440008407847

Riches, G., \& Dawson, P. (1996). Communities of feeling: The culture of bereaved parents. Mortality 1, 143-162. https://doi.org/10.1080/713685832

Semino, E. (2011). Metaphor, creativity, and the experience of pain across genres. In J. Swann, R. Carter and R. Pope (Eds.), Creativity, Language, Literature: The State of the Art. Basingstoke: Palgrave Macmillan, pp. 83-102. https://doi.org/10.1007/978-1-349-92482-0_6 
Uren, T.H., \& Wastell, C.A. (2002). Attachment and meaning-making in perinatal bereavement. Death Studies 26(4), 279-308. https://doi.org/10.1080/074811802753594682

Walker, J.L.G., \& Walker, B.M. (2015). Unscripted Loss: A Hesitant Narrative of a Reconstructed Family. In R.E. Silverman \& J. Baglia (Eds.), Communicating Pregnancy Loss: Narrative as a Method for Change. New York: Peter Lang, pp. 59-71.

Williams-Whitney, D., Mio, J.S., \& Whitney, P. (1992). Metaphor production in creative writing. Journal of Psycholinguistic Research 21(6), 497-509.

\section{Appendix 1. Participant information}

\section{Support workers:}

\begin{tabular}{|c|c|}
\hline Interview code & Gender \\
\hline $\mathrm{WP}_{3}$-T1-Support-04/05/2017 & $\mathrm{F}$ \\
\hline $\mathrm{WP}_{3}$-T2-Support-04/05/2017 & $\mathrm{F}$ \\
\hline $\mathrm{WP}_{3}-\mathrm{T}_{3}$-Support-11/05/2017 & $\mathrm{F}$ \\
\hline $\mathrm{WP}_{3}-\mathrm{T}_{4}$-Support-11/05/2017 & $\mathrm{F}$ \\
\hline $\mathrm{WP}_{3}-\mathrm{T}_{5}$ - Support -12/05/2017 & $\mathrm{F}$ \\
\hline $\mathrm{WP}_{3}$-T6- Support -16/05/2017 & $\mathrm{F}$ \\
\hline $\mathrm{WP}_{3}-\mathrm{T}_{7}-\mathrm{S}$ Support -16/05/2017 & $\mathrm{F}$ \\
\hline $\mathrm{WP}_{3}$-T8- Support 17/05/2017 & $\mathrm{F}$ \\
\hline $\mathrm{WP}_{3}$-T9- Support -19/05/2017 & $\mathrm{F}$ \\
\hline $\mathrm{WP}_{3}$-T10- Support -24/05/2017 & $\mathrm{F}$ \\
\hline $\mathrm{WP}_{3}-\mathrm{T}_{11}$ - Support -24/05/2017 & $\mathrm{F}$ \\
\hline $\mathrm{WP}_{3}$-T12- Support-30/05/2017 & $\mathrm{F}$ \\
\hline $\mathrm{WP}_{3}$-T13-Support-01/06/2017 & $\mathrm{F}$ \\
\hline $\mathrm{WP}_{3}$-T14-Support-19/06/2017 & $\mathrm{F}$ \\
\hline $\mathrm{WP}_{3}-\mathrm{T}_{14}$ - Support-22/o6/2017 & M \\
\hline $\mathrm{WP}_{3}-\mathrm{T}_{15}$ - Support-25/07/2017 & $\mathrm{F}$ \\
\hline
\end{tabular}

\section{Key to filenames:}

$\mathrm{WP}_{3}=$ work package 3

$\mathrm{T} 1-\mathrm{T}_{16}=$ Transcript number 
The Bereaved

\begin{tabular}{|c|c|c|c|}
\hline Type of pregnancy loss & Interview code & Gender & Age \\
\hline M & $\mathrm{WP}_{4}-\mathrm{T} 6-\mathrm{M}-5-29 / 09 / 2017$ & $\mathrm{~F}$ & 32 \\
\hline M & $\mathrm{WP}_{4}-\mathrm{T}_{7}-\mathrm{M}-6-29 / 09 / 2017$ & $\mathrm{~F}$ & 34 \\
\hline M & $\mathrm{WP}_{4}-\mathrm{T} 8-\mathrm{M}-7-02 / 10 / 2017$ & $\mathrm{~F}$ & 26 \\
\hline M & $\mathrm{WP}_{4}-\mathrm{T}_{9}-\mathrm{M}-8-03 / 10 / 2017$ & $\mathrm{~F}$ & 35 \\
\hline FA & $\mathrm{WP}_{4}-\mathrm{T} 10-\mathrm{FA}-2-11 / 10 / 2017$ & $\mathrm{~F}$ & 34 \\
\hline FA & $\mathrm{WP}_{4-\mathrm{T}} 11-\mathrm{FA}-3-16 / 10 / 2017$ & $\mathrm{~F}$ & 26 \\
\hline FA & $\mathrm{WP}_{4}-\mathrm{T} 18-\mathrm{FA}-7-17 / 10 / 2017$ & $\mathrm{~F}$ & 32 \\
\hline M & $\mathrm{WP}_{4}-\mathrm{T} 12-\mathrm{M}-9-20 / 10 / 2017$ & $\mathrm{~F}$ & 35 \\
\hline S & $\mathrm{WP}_{4}-\mathrm{T} 13-\mathrm{S}-1-25 / 10 / 2017$ & $\mathrm{~F}$ & 34 \\
\hline FA & $\mathrm{WP}_{4}-\mathrm{T} 14-\mathrm{FA}-4-30 / 10 / 2017$ & $\mathrm{~F}$ & 28 \\
\hline FA & $\mathrm{WP}_{4}-\mathrm{T} 19-\mathrm{FA}-8-31 / 10 / 2017$ & $\mathrm{~F}$ & 37 \\
\hline FA & $\mathrm{WP}_{4-\mathrm{T}} 15-\mathrm{FA}-5-01 / 11 / 2017$ & $\mathrm{~F}$ & 43 \\
\hline S & $\mathrm{WP}_{4}-\mathrm{T} 16-\mathrm{S}-2-03 / 11 / 2017$ & $\mathrm{~F}$ & 33 \\
\hline $\mathrm{FA}(+\mathrm{M})$ & $\mathrm{WP}_{4}-\mathrm{T} 17-\mathrm{FA}-6-05 / 11 / 2017$ & $\mathrm{~F}$ & 35 \\
\hline $\mathrm{M}$ & WP4-T20-M-10-07/11/2017 & $\mathrm{F}$ & 41 \\
\hline FA & $\mathrm{WP}_{4}-\mathrm{T} 21-\mathrm{FA}-9-10 / 11 / 2017$ & $\mathrm{~F}$ & 33 \\
\hline FA & $\mathrm{WP}_{4}-\mathrm{T} 22-\mathrm{FA}-10-14 / 11 / 2017$ & $\mathrm{~F}$ & 43 \\
\hline S & $\mathrm{WP}_{4}-\mathrm{T}_{23}-\mathrm{S}-3-07 / 11 / 2017$ & $\mathrm{~F}$ & 34 \\
\hline M & $\mathrm{WP}_{4}-\mathrm{T} 24-\mathrm{M}-11-14 / 11 / 2017$ & $\mathrm{~F}$ & 31 \\
\hline S & $\mathrm{WP}_{4}-\mathrm{T}_{25}-\mathrm{S}_{4}-14 / 11 / 2017$ & $\mathrm{~F}$ & 37 \\
\hline S & $\mathrm{WP}_{4}-\mathrm{T} 26-\mathrm{S}-5-15 / 11 / 2017$ & $\mathrm{~F}$ & 43 \\
\hline S & $\mathrm{WP}_{4}-\mathrm{T} 27-\mathrm{S} 6-20 / 11 / 2017$ & $\mathrm{~F}$ & 39 \\
\hline S & $\mathrm{WP}_{4}-\mathrm{T} 28-\mathrm{S}-7-20 / 11 / 2017$ & $\mathrm{~F}$ & 32 \\
\hline S & $\mathrm{WP}_{4}-\mathrm{T} 29-\mathrm{S}-8-22 / 11 / 2017$ & $\mathrm{~F}$ & 34 \\
\hline S & $\mathrm{WP}_{4}-\mathrm{T}_{30} \mathrm{O}-\mathrm{S}-924 / 11 / 2017$ & $\mathrm{~F}$ & 40 \\
\hline FA & $\mathrm{WP}_{4}-\mathrm{T}_{31-\mathrm{FA}}-11-27 / 11 / 2017$ & $\mathrm{~F}$ & Not given \\
\hline $\mathrm{FA} / \mathrm{S}$ & $\mathrm{WP}_{4}-\mathrm{T}_{32}-\mathrm{FA}-\mathrm{P}_{1-17 / 01 / 2018}$ & M & 45 \\
\hline$S$ & $\mathrm{WP}_{4}-\mathrm{T}_{33}-\mathrm{S}-\mathrm{P}_{2-19} / 01 / 2018$ & M & 42 \\
\hline S & $\mathrm{WP}_{4}-\mathrm{T}_{34}-\mathrm{S}_{-} \mathrm{P}_{3}-20 / 02 / 2018$ & M & 34 \\
\hline S & $\mathrm{WP}_{4}-\mathrm{T}_{35}-\mathrm{S}-\mathrm{F}_{4}-02 / 02 / 2018$ & $\mathrm{~F}$ & 42 \\
\hline
\end{tabular}

\section{Key to filenames:}

$\mathrm{WP}_{4}=$ Work package number

T1-35 = Transcript number

$\mathrm{M}=$ Miscarriage

$\mathrm{S}=$ Stillbirth

$\mathrm{FA}=$ Termination following diagnosis of foetal abnormality 


\section{Appendix 2. Metaphor categories}

No. of instances

(out of a total of

Metaphor

2691 annotated

Rank category

Example

instances)

1. Reification

Be as kind to yourself as you can giving yourself time

839

and space $^{\star}$

2. Moving ego

it feels impossible to shift and move forward and

3. Journey imagine that they'll ever get beyond this moment

s'pose is congruent with their conceptualisation of their experience

I'm veering one way or the other

4. Physical

they don't quite grasp where a bereaved person is

location

it's meeting parents where they are in their grief as well

5. Body-related

what is your gut feeling, what's your, what's your heart or embodied saying, are you gonna remain broken forever like this metaphors

6. Animacy

7. Container

time would heal for her

when you're grieving you can sort of enter sort of a grief world where you start to push, push people away

8. $\quad$ Divided self

My brain was obviously still in shock mode

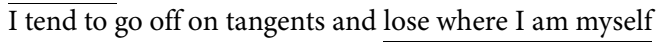

9. Seeing

sort of be there, available to them with u- utter kindness, patience, tolerance, understanding, non-assumptive presence and just witness their struggle

10. Agency, lack it's like a rollercoaster that's, like, throughout the day, of agency throughout weeks, days, weeks, like that - sometimes in an hour in those first, you know, months

11. Being moved, It's made me think a lot more about myself acted upon

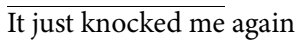

12. Crumbling, He totally fell apart breaking, Your heart breaks a bit

falling apart,

fixing, mending

13. Fighting or You need to stand your ground and you need to fight

Battling or

You kind of think that's it, you've won

Struggling

14. Physical It causes me so much pain to know that that's what sensation and happened pain

Now I was numb to it 
Metaphor

Rank category

Example instances)

15. Presence, It will always be with me

accompanying That really stuck with him

and absence

16. Opening and I'm quite open

closing I guess it was just a way of closing things off

17. Up and Down That was probably one of the lowest points

18. Movement having to go through that knowing your baby is is dead you've sort've pushed back

19. Violence and you're sort of being bombarded with phrases impact

if it was my first pregnancy I really think it would have hit us both harder

20. Nature

before she was an absolute rock you know you've got to try $\overline{\text { and }}$ step into their shoes and see it from their eyes you know what are they seeing what's their world what's their landscape

21. Space was quite nice, just to kind of um, be able to have the space to process really after that are you gonna have another one to fill the void

22. Bonds, I can only call it a procedure cause I think I've detached connections myself

I'd had time to get attached

23. Machine your brain shuts down

I'm taken upstairs to what I can only describe as a conveyor belt

24. Obstacles just felt like he had to suddenly just get over it I couldn't get my head round it

25. Order and I agreed to the natural birth I was tired I was hungry I disorder was really emotional I was just in a mess at the time I just wasn't thinking straight

26. Stages

it was like we passed that milestone sort of plot the next steps forward

27. Liquid-based the safest place for him was on the ward getting on with metaphors stuff and bottling things up

I got to the point where the emotions just had to spill out

28. Closeness and I've lost friends that have that have distanced themselves distance um because they don't know how to act with me but I feel just that I need to keep them away from this just a little bit 
No. of instances

Rank $\begin{array}{ll}\text { Metaphor } \\ \text { category }\end{array}$

(out of a total of

Example

2691 annotated

29. Process

it was nice to sort've round it off I guess but beyond that instances)

I don't know what they could offer me

I knew we would come through it at the other end $i$ never once thought i don't think I'm $\overline{\text { gonna get out of }}$ this

30. Darkness and reading through it you can see actually I was in quite a light

dark place there

I've seen some genuine kindness from people. and you know you're thinking at this there are there've been some bright moments

31. Carrying I think I'd just got all the stuff going around in my head that I just needed to say out loud, offload to someone talked through options and kinda gave you lots of things to take away knowing that it might be too much for me to take on board

32. Not feeling you come out of hospital and the world is still carrying part of the on but your world has stopped world, having just it's not a nice world to be in. at all different realities

33. Moving time I knew that this awful moment was coming and I was just avoiding it

I find it quite difficult now that the time's moved on

34. Sense of touch I think we're all just feeling our way through really you know I'm touched by grief in a way that I I'd never lost anyone really before

35. Letting go We were going to scatter his ashes on his due date but I physically, don't feel ready to let him go holding on started talking about it she'd held onto that grief for fifty years

36. Project

yeah life isn't perfect and life hasn't gone to plan successfully battled infertility and that's the job done

37. Conduit hopefully that will get the message across because you Metaphor know someone says asks you how are you you're like oh god I don't know where to begin yeah that's it's just trying to kind've get that across

38. Silence and We had a couple of friends two of our closest friends or 26 Noise very close friends um radio silence for three? Four weeks? Cause they thought we needed space. We thought they were ignoring us it was you know you get echoes of the first birth and the first pregnancy as well. That was quite traumatic um for both of us 
Metaphor

Rank category

Example

2691 annotated

39. Straight and

at the time I just wasn't thinking straight. Everything

instances)

not straight

was such a mess you don't really take in what people're

saying properly

so it kind of spiralled from there

40. Pressure

I felt so much pressure from them which I shouldn't feel

was like trying to force me to do it cause they was

thinking I will regret it but I knew what is the best for me in that moment

41. Physical

you're meant to be this kind of strong kind of pillar and

strength

something like this it can knock you down so easily

when I'd finally built up the strength to kind of talk to

her about what had happened

42. Fairness,

I've thought actually why should I be the one that's

justice

spared?

it was just a blessing a real blessing

43. Pushing and you were having to push and battle with the system to pulling get the process started

would have to deliver the baby and didn't know if the baby would pull through

44. $\quad$ Hiding

They weren't telling me the whole truth they were

hiding behind things

Try not to do the thing that we always do which is try and hide grief and try and recognise um that that baby as a real child

45. Size

for me the big thing was the fear of the future

life keeps moving on but there's this big chunk of our

life which is missing

46. Games, this just seems really pointless doesn't it because all the

odds are stacked against me here

obviously I knew at one point it was gonna be game over and that really upset me

47. Levels we're very fortunate that we've got those friends so we've got another layer of understanding

this hurts and this affects us on a very deep level

48. Going back didn't know if I was coming or going and forth oh no I think I've gone back too soon I thought I was okay I wanted to get back some normality

49. Depth

you're hoping for an answer that they can't give you.

And you know that deep in your heart

Because you've still got to go into depth all of your

feelings and emotions and I think with miscarriage you

don't know what they are for a while 
No. of instances

Metaphor

(out of a total of

Rank category

Example

2691 annotated

\begin{tabular}{ll}
\hline 50. Searching and & $\begin{array}{l}\text { sometimes you can't find the words } \\
\text { finding }\end{array}$ \\
& positive pregnancy test you don't really have any hope \\
& left it's all gone so I'd managed to find this sort've little \\
& window of hope
\end{tabular}

instances)

51. Guiding,

someone could help you with the decision. and steer

leading,

you with it a bit

16

following

screening can then lead to making really difficult

decisions

52. Balance I had no idea it was going to make me mentally quite so

unstable for quite so long

the morning of it though I had a bit of a wobble in the sense that I hadn't named her

53. Visibility and really want to die in that moment in that room cause invisibility

everything what I was waiting for just vanished

All those hopes and dreams overnight suddenly just vanished and that's what I struggled with

54. Speed

I can't really remember it almost it was all a bit of a blur understand what pace they want things to happen at

55. Exploring we both just burst into tears I just ended up going to the GP saying look we don't need to explore this fertility thing any more

I never explored those options

56. Weight

I guess I don't know how to explain the emotions really crushing I suppose

it wasn't something we took lightly by any means

57. Temperature quite cold I didn't feel there was any kind of empathy I don't want that to sound kind of cold or heartless of anything whatever works for everyone is fine but for me it was remembering that that I had said my goodbyes

58. Finding and you're excited about the future and you make plans and losing things once that's lost the first time that never ever comes back again

feel part of me is missing

59. Life and

that kills me cos I I cannot imagine kind of erm

Death

carrying on you know with with my life as it is

I'm just doing what I'm doing to survive really

6o. Tangling and Try and untangle that all from yeah the trauma of what untangling happened to me

the other um lady I saw was just very good at helping me unpick how I felt about a lot of these 
No. of instances

(out of a total of

Metaphor

2691 annotated

Rank category

Example

instances)

61. Cleanliness, had a massage and a facial felt like I was cleansing and

dirtiness

purifying myself

I wanted a fresh start

62. Changing, you have to try and rebuild yourself and your

adjusting,

confidence and everything

developing

as we've been going along you evolve

and evolving

63. Safety, I just like to be at home and prefer the quiet life so

protection, danger

home's been my sanctuary

for us it felt as if that was enough security um it was like we we passed that milestone of twelve weeks and

everything was gonna be fine

64. Circular

an impossible circle trying to find out information

9

motion

she apologised for the wording in the letter and you just go round in circles you know

65. Medical cure the baby is kind of the antidote to the misery really it's a plaster it's not gonna solve the problem

66. Transparency During the first session we make all the boundaries

and clear

opaqueness

$\overline{\text { well }}$ once a test comes back clear it's fine

67. Physical some kind've like healing moment I don't really know injury what happened but they were obviously all in this room with this dead baby and um [NAME] was really proud that it was her son

I don't feel the need to keep opening that wound again and again for me what's important is that we heal and we move forward

\footnotetext{
* In this paper, relevant metaphorical phrases in each example are underlined. It should be noted that not all metaphors in each example are identified or discussed. This is not restricted to the level of the word; words from the surrounding context may be included for clarity where this is necessary for understanding of the metaphor.
} 


\section{Appendix 3. Topics identified in the data and the number of times metaphor was used to talk about each of these topics}

These topics were identified in interviews with women who had experienced pregnancy loss, their partners, and those who support them.

\begin{tabular}{|c|c|}
\hline Topics & $\begin{array}{c}\text { Number of times metaphor was used to talk about } \\
\text { each of these topics }\end{array}$ \\
\hline Advice & 22 \\
\hline Anger & 24 \\
\hline Asking for support & 10 \\
\hline Attitudes towards others & 15 \\
\hline Awareness, self-awareness & 21 \\
\hline Baby and absence of baby & 129 \\
\hline Becoming a different person & 64 \\
\hline Becoming a supporter & 4 \\
\hline Becoming pregnant & 36 \\
\hline Becoming pregnant again & 87 \\
\hline Behaviour in support group meeting & 18 \\
\hline Being reminded of the loss & 31 \\
\hline Communication & 346 \\
\hline Community-forming - not alone & 75 \\
\hline Continued existence of baby & 116 \\
\hline Dads & 101 \\
\hline Dealing and not dealing with the loss & 349 \\
\hline Decision-making about pregnancy & 127 \\
\hline Diagnosis & 88 \\
\hline $\begin{array}{l}\text { Disenfranchised grief - not given } \\
\text { permission to grieve }\end{array}$ & 11 \\
\hline $\begin{array}{l}\text { Distinction between miscarriage and } \\
\text { stillbirth }\end{array}$ & 5 \\
\hline Emotional effects - other, general & 404 \\
\hline $\begin{array}{l}\text { Ensuring that something good came out } \\
\text { of it }\end{array}$ & 29 \\
\hline Existence of baby & 92 \\
\hline Failure and guilt & 33 \\
\hline Family, partners, relationships & 152 \\
\hline Fear, anxiety & 31 \\
\hline Feelings of 'going crazy' & 12 \\
\hline Funeral and or cremation & 20 \\
\hline Grief, sadness and upset & 178 \\
\hline Helping others & 23 \\
\hline Hopes and expectations & 15 \\
\hline
\end{tabular}


Number of times metaphor was used to talk about

Topics each of these topics

Images, symbols $\quad 88$

Isolation $\quad 25$

Judgement 8

Labour, birth $\quad 75$

Lack of care, insufficient care $\quad 53$

Lack of choice, options, control 21

Lack of information $\quad 39$

Language and terminology $\quad 86$

Law 7

Loss of future $\quad 43$

Making choices $\quad 124$

Marking time \& dates $\quad 25$

Meaning-making 18

Medical care unmarked $\quad 186$

Medical support organisations 3

Memory-making $\quad 254$

Miscarriage 60

$\begin{array}{ll}\text { Mother's body, intuition about } & 67\end{array}$

Nonsensical ideas, ideas accepted to be $\quad 8$

illogical

Normality 23

Not knowing $\quad 22$

$\begin{array}{ll}\text { Parenthood } & 17\end{array}$

Pregnancy (unmarked) $\quad 114$

Pregnancy loss (unmarked) $\quad 366$

Reactions of others $\quad 204$

Recovery, improvement and acceptance $\quad 142$

Remains and decisions about remains $\quad 113$

Rites and rituals $\quad 139$

Shared understanding (or lack of) $\quad 24$

Siblings $\quad 42$

Support (general) $\quad 239$

Support Organisation or Group $\quad 82$

Methods of support offered $\quad 17$

Taboo or silence in society $\quad 66$

Talking about it - the bereaved $\quad 218$

$\begin{array}{ll}\text { Termination } & 129\end{array}$

Types of loss $\quad 29$

Unexpectedness 7

Validation, loyalty to baby's memory, $\quad 122$

and legacy 


\section{Address for correspondence}

Jeannette Littlemore

University of Birmingham

Department of English Language and Applied Linguistics

3 Elms Road, Edbbaston

Birmingham B15 2TT

UK

j.m.littlemore@bham.ac.uk

\section{Biographical notes}

Jeannette Littlemore is a Professor of Applied Linguistics at the University of Birmingham, UK.

Sarah Turner is a Lecturer in Stylistics at Coventry University, UK. 